\title{
ON THE JUBILEE OF THE ALL-RUSSIA RESEARCH INSTITUTE OF METROLOGICAL SERVICE
}

On October 1, 2010, the All-Russia Research Institute of Metrological Service (VNIIMS) celebrated its 110th year, after a complicated journey from the Moscow assayers office under the Moscow region assayers administration to the State scientific metrological institute of the National Standards Department. The history of the institute is discussed in an article by its director, Dr. S. A. Kononogov, in a special issue of the journal Istoriya Nauki i Tekhniki (History of Science and Technology), No. 9, 2010.

As in the past, VNIIMS is the main scientific metrological center of the country for legal metrology, in accordance with which groups of interrelated and mutually dependent common technical and legal rules, specifications, and standards subject to state regulation are set up to ensure the uniformity of measurement with the cooperation of competent agencies.

In addition, in the past few years at VNIIMS there has been further work on fundamental metrology and research on the role of the fundamental physical constants in metrology, aimed in particular at preparing for a redefinition of several of the fundamental SI units. Today a number of projects are under way in connection with the tasks of the Federal Targeted Program on Development of the Infrastructure for the Nanotechnology Industry in the Russian Federation during 2008-2009, established by the government of the Russian Federation on August 2, 2007. VNIIMS headed working group No. 3 on Developing the Methodological Component of the Infrastructure for the Nanotechnology Industry, which primarily involves steps to ensure the uniformity of measurements and the creation of new measurement capabilities.

As the coordinator of work on metrology in international and intergovernmental (International Organization for Legal Metrology, the international organs of the Metric Convention) and regional (COOMET, NTKmetr in the CIS, the AsianPacific Forum on legal metrology, etc.) organizations, VNIIMS occupies a key position, as before, through its participation in comprehensive international activities, especially in the area of legal metrology. As a participant in the Agreement on Mutual Recognition of National Standards and Calibration and Measurement Certificates Issued by National Metrological Institutes, VNIIMS works to guarantee the quality and reliability of its calibration and measurement capabilities, thereby participating in the formation of an international market for metrological services.

VNIIMS has always provided effective assistance to various branches of the national economy. The spectrum of metrological services that are provided is quite broad: from tests, calibrations, consultations, document preparation, raising the qualifications of specialists to metrological expertise in the most complicated of projects (for example, Sakhalin-2, etc.), and creating documentation for the development of complex infrastructures (the national railway RZhD, etc.).

Today the major document defining the development of basic and applied metrology in Russia for the next few years is the Strategy for Ensuring Uniformity of Measurement in Russia to 2015, issued by the Ministry of Industry and Trade of the Russian Federation in June 2009. A number of articles to be published in the journal Izmeritel'naya Tekhnika (Measurement Techniques) during the VNIIMS jubilee year will deal with specific problems now being solved by the institute's staff.

Translated from Izmeritel'naya Tekhnika, No. 11, p. 3, November, 2010. 